\title{
Nail involvement in adult patients with plaque-type psoriasis: prevalence and clinical features *
}

\author{
Karen Regina Rosso Schons ${ }^{1}$ \\ Maristela de Oliveira Beck²
}

\author{
André Avelino Costa Beber ${ }^{2}$ \\ Odirlei André Monticielo ${ }^{3}$
}

DOI: http:/ / dx.doi.org/10.1590/abd1806-4841.20153736

\begin{abstract}
A bstract: BACKGROUND: Psoriasis is a disease of worldwide distribution with a prevalence of 1 to $3 \%$. Nail psoriasis is estimated in $50 \%$ of patients with psoriasis, and in the presence of joint involvement, it can reach $80 \%$.

Овјестіvе: To study the nail changes - and their clinical implications - presented by patients with psoriasis vulgaris under surveillance in a university hospital from the south of Brazil.

Methods: This cross-sectional study evaluated 65 adult patients from January 2012 to March 2013. Cutaneous severity was assessed according to the Psoriasis Area and Severity Index (PASI). The Nail Psoriasis Severity Index (NAPSI) was used to evaluate patient's nails. The diagnosis of psoriatic arthritis was established according to the Classification Criteria for Psoriatic Arthritis (CASPAR).

RESULTS: The prevalence of NP was 46.1\%. These patients had a median [interquartilic range (IQR)] NAPSI of 1 (015). A total of $63.3 \%$ of patients reported aesthetic discomfort or functional impairment related to their nails. Onycholysis was the most common feature $(80 \%)$. When compared with patients without nail involvement, patients with NP had lower mean age at psoriasis onset [21 (18-41) vs. 43 (30-56) years, p=0,001]; longer disease duration [15.5 (10-24) vs. 6 (2-12) years, p=0.001]; higher PASI [9.2 (5-17) vs. 3.7 (2-10), p=0.044], higher frequency of psoriatic arthritis (43.3 vs. 3.7, $\mathrm{p}=0.002)$ and more often reported family history of psoriasis $(40 \% \mathrm{vs} .7 .4 \%, \mathrm{p}=0.011)$. CONCLUSION: Onycholysis was the most frequent finding and most patients feel uncomfortable with the psoriatic nail changes that they experience.
\end{abstract}

Keywords: Dermatology; Nails; Psoriasis

\section{INTRODUCTION}

Psoriasis is a chronic inflammatory disease of multifactorial pathogenesis involving immunological, genetic and environmental causes. ${ }^{1}$ Although psoriasis can present at any age, onset before the age of 30 is more common, so that most patients are affected at the most productive stage of their lives. ${ }^{2}$

The nails are considered a modified specialization of the skin and are commonly affected by the disease, presenting in up to $80 \%$ of the patients. ${ }^{3-5}$ The clinical signs of nail involvement in psoriasis are heterogeneous and related to the effects of the disease in either the mathrix, the nail bed or the periungueal tissue, which results in distinct injury patterns. ${ }^{6}$ In psoriasis, nail involvement implies important psychological stress, pain and decreased functionality. It may represent more severe forms of cutaneous psoriasis and be a predictor of joint inflammation. ${ }^{6-11}$
In Brazil, epidemiological data on psoriasis are scarce, and so are the data about the nail disease. The aim of this study was to evaluate nail involvement in patients with plaque-type psoriasis, and determine it's prevalence, clinical features and possible associations.

\section{PATIENTS AND METHODS}

This cross-sectional study was conducted from January 2012 to March 2013. During this period, all patients with plaque-type psoriasis over the age of 18 years who attended the Dermatology Department of the University Hospital of Santa Maria, located in Santa Maria, Rio Grande do Sul state, were invited to participate in the study. Sampling was done by convenience. All patients who met the eligibility criteria were invited to join the study and responded according to their availability. All data collection was performed by the same researcher.

\footnotetext{
Received on 01.06.2014

Approved by the Advisory Board and accepted for publication on 13.07.2014

Financial Support: None.

Conflict of Interest: None.

Study conducted at the University Hospital of Santa Maria (HUSM- UFSM) - Santa Maria (RS), Brazil. 
The research was conducted according to the rules of Resolution 196/96 of the National Health Council, which regulates research with human subjects in Brazil. The study project was approved by the Ethics Committee of the Federal University of Santa Maria. All patients received and provided written consent to participate in the study.

Patients answered a specific questionnaire about the following demographic variables: gender, age, occupation, skin phototype, disease duration, age at disease onset, family history of psoriasis, current medications and comorbidities. Patients with nail psoriasis (NP) were also questioned: "do you experience any sort of aesthetic or functional discomfort in your daily life due to the nail problem?"

Psoriasis skin severity at the time of the physical examination was assessed by using the Psoriasis Area and Severity Index (PASI). ${ }^{12,13}$ All patients had their nails examined for nail disorders related to psoriasis. If onychomycosis was suspected, based on nail features such as onychorrhexis, hyperkeratosis, thickening or crumbling, direct microscopy examination and mycological culture were performed. ${ }^{14}$ Patients with onychomycosis, even though they could present other features related to NP, were excluded from this group. Patients with NP were then evaluated according to the NAPSI Nail Psoriasis Severity Index (NAPSI). 15,16

The collected data were submitted to statistical tests in the software SPSS 17.0 (SPSS Inc., IBM Corporation, Armonk, New York). Cathegorical variables were represented by percentages and analyzed by Chi square test or Fisher's exact test. Variables had their normality verified by Kolmogorov-Smirnov test. Continuous variables with normal distribution were tested by $\mathrm{T}$ student test and the results were presented as mean \pm standard deviation. For continuous variables with an abnormal distribution, the Mann Whitney test was performed. The central tendency measure used was median and its corresponding interquartile range. Statistical significance was considered at a level of $5 \%(p<0.05)$ for all tests.

\section{RESULTS}

A total of 65 patients with plaque-type psoriasis were included in this study. Their main clinical and demographic characteristics are summarized in table 1. The sample consisted mostly of women $(64.6 \%)$ and the mean age was $49 \pm 14.6$ years. The main occupation reported was farming and the majority of patients had skin color phototype III (61.5\%), according to Fitzpatrick. ${ }^{17}$ The mean disease duration was $14 \pm 10.5$ years and the mean age of disease onset was $34.8 \pm 16.4$ years, with a minority of patients reporting onset after the age of $60(7.7 \%, \mathrm{n}=5)$. Most patients $(69.2 \%)$ had skin severity classified as mild (PASI $\leq 10) .{ }^{18,19}$ The sample consisted mostly of patients who were under treatment for psoriasis $(84.6 \%)$. Of these, $56.9 \%$ were using topical corticosteroids, $64.6 \%$ were using emollient creams and $44.6 \%$ were taking systemic drugs. No patients were under topical treatment for the nails or periungual tissues or being treated with phototherapy or immunobiological therapy.

A total of $70.7 \%$ of patients had some type of medical comorbidity. Among these, hypertension was the most prevalent comorbidity $(38.5 \%)$, followed by diabetes mellitus $(20 \%)$ and smoking (15.4\%). Other less frequently reported comorbidities were ischemic heart disease $(n=3)$, renal failure $(n=2)$ and ulcerative

TABLE 1: Characteristics of patients with plaque-type psoriasis $(n=65)^{*}$

\begin{tabular}{|c|c|}
\hline Characteristic & Statistics \\
\hline Female gender & $42(64.6)$ \\
\hline Age, years ${ }^{a}$ & $49 \pm 14.7$ \\
\hline Men ${ }^{\mathrm{a}}$ & $45 \pm 14.1$ \\
\hline Women $^{\mathrm{a}}$ & $51.8 \pm 15.5$ \\
\hline \multicolumn{2}{|l|}{ Occupation } \\
\hline Farmers & $22(33.8)$ \\
\hline Housekeepers & 11 (16.9) \\
\hline sellers & $7(10.7)$ \\
\hline Othersb & $25(38.4)$ \\
\hline Fitzpatrick's phototype III & $40(61.5)$ \\
\hline PASIa & $8.3 \pm 7.4$ \\
\hline$\leq 10$ & $45(69.2)$ \\
\hline$>10$ & $20(30.8)$ \\
\hline Psoriasis onset, yearsa & $34.9 \pm 16.4$ \\
\hline$<20$ & $15(23.1)$ \\
\hline $20-59$ & $45(69.2)$ \\
\hline$\geq 60$ & $5(7.7)$ \\
\hline Disease duration, yearsa & $14 \pm 10.5$ \\
\hline Family history of psoriasis & $16(24.6)$ \\
\hline Current treatment & $55(84.6)$ \\
\hline Systemic & $29(44.6)$ \\
\hline Topical & $49(75.3)$ \\
\hline Onicomychosis & $8(12.3)$ \\
\hline Nail psoriasis & $30(46.1)$ \\
\hline Comorbidities & $46(70.7)$ \\
\hline $\mathrm{ASH}$ & $25(38.4)$ \\
\hline $\mathrm{DM}$ & $13(20)$ \\
\hline Smoking & $10(15.4)$ \\
\hline Othersc & $16(24.6)$ \\
\hline Psoriatic Arthritis & $16(24.6)$ \\
\hline
\end{tabular}

PASI, Psoriasis Area and Severity Index. DM, Diabete Mellitus. ASH, Artherial Sistemic Hypertension

*All data are presented as the number of individuals $=n(\%)$, unless otherwise described

${ }^{\text {a }}$ Data expressed in median \pm standard deviation

b Other occupations: housemaid $(n=6)$; driver, manicure, student $(n=3)$; teacher $(n=2)$; cook, accountant, cobbler, mason, administrator, painter, electrician and butcher $(n=1)$

${ }^{c}$ Other comorbidities: ischemic heart disease $(n=3)$; renal failure, ulcerative colitis ( $n=2)$; hypothyroidism, tumors of the central nervous system, depression, prostate cancer, asthma, allergic rhinitis, autoimmune hepatitis and polyarteritis nodosa $(n=1)$ 
colitis $(\mathrm{n}=2)$. Hypothyroidism, central nervous system tumor, depression, prostate cancer, asthma, allergic rhinitis, autoimmune hepatitis and polyarteritis nodosa were observed in only one patient each.

Of the 65 patients who participated in the study, 8 were diagnosed with onychomycosis $(12.3 \%)$. Even though these patients also presented findings compatible with NP, they did not receive this diagnosis. NP was then diagnosed in 16 women and 14 men, which accounted for a prevalence of $46.1 \%(n=30)$. The median [interquartile range (IIQ)] NAPSI overall score obtained was 1 (0-15). Most patients with NP had involvement of both hands and feet $(70 \%, n=21)$, while exclusive involvement of the feet occured in $10 \%(n=3)$ of cases and exclusive involvement of the hands was observed in $20 \%(n=6)$ of cases. Both hands were frequently involved: the left hand was affected in $80 \%$ of cases and the righ hand was affected in $73.3 \%$ of patients. The left foot was involved in $76.7 \%$ of cases and the left foot in $73.3 \%$. When nail changes were observed, more than one pattern was often found [2 (1.7-3.2)], and these changes were observed in the same nail or in different nails. The median number of affected nails was 1 (IIQ 0-8, n=243 nails). Onycholysis was the most frequent pattern, seen in 24 patients $(80 \%)$, followed by subungual hyperkeratosis $(66.7 \%$, $n=20)$ and by oil stains (43.3\%, $n=13)$. No significant differences related to these findings were found between genders. Details on the morphological types of nail changes found in patients with NP are described in table 2.

The comparison between groups where nail psoriasis was present or absent is described in table 3. When both groups were compared by age, gender and presence of comorbidities, no statistically significant differences were found. When compared with patients

TABLE 2: Morphology of nail patterns in patients with psoriasis $(n=30)^{*}$

\begin{tabular}{|c|c|c|c|c|}
\hline Finding & $\begin{array}{l}\text { Prevalence } \\
\text { (n) }\end{array}$ & $\begin{array}{l}\text { Women } \\
(n=16)\end{array}$ & $\begin{array}{l}\text { M en } p^{* *} \\
(n=14)\end{array}$ & \\
\hline Onicholysis & $24(80)$ & $12(75)$ & $12(85.7)$ & 0.657 \\
\hline $\begin{array}{l}\text { Subungueal } \\
\text { hyperkeratosis }\end{array}$ & $20(66.7)$ & $9(56.3)$ & 11 (78.6) & 0.260 \\
\hline Oil drops & $13(43.3)$ & $7(43.8)$ & $6(42.9)$ & 0.961 \\
\hline Pitting & 10 (33.3) & $6(37.5)$ & $4(28.6)$ & 0.709 \\
\hline $\begin{array}{l}\text { Splinter } \\
\text { hemorrhages }\end{array}$ & $8(26.7)$ & $2(12.5)$ & $6(42.9)$ & 0.101 \\
\hline Leukonychia & $8(26.7)$ & $4(25)$ & 4 (28.6) & $>0.999$ \\
\hline Crumbling & 4 (13.3) & $2(12.5)$ & $2(14.3)$ & $>0.999$ \\
\hline Red spots & $1(3.3)^{\prime}$ & $1(6.5)$ & $0(0)$ & $>0.999$ \\
\hline
\end{tabular}

${ }^{*}$ All data are presented as the number of individuals $=n(\%)$, unless otherwise described ${ }^{* *} p$ value was calculated by Fisher exact test without nail involvement, patients with NP showed lower median age of psoriasis onset [21 (18-41) vs. 43 (30-56) years, $\mathrm{p}=0.001]$ and longer skin disease duration [15.5 (10-24) vs. 6 (2-12), p=0.001]. This group also showed a higher frequency of psoriatic arthritis (43.3\% vs. 3.7\%, $\mathrm{p}=0.002)$ and higher median PASI [9.2 (5-17) vs. $3.7(2-10), p=0.044]$. Family history of psoriasis was negative in most patients in both groups, but when NP was present, a positive family history was more often reported $(40 \%$ vs. $7.41 \%$, $\mathrm{p}=0.011)$.

The prevalence of psoriatic arthritis was $24.6 \%$ : 10 patients were women and 6 patients were men. The comparison between groups of patients with and without psoriatic arthritis is described in table 4 . We found no statistically significant differences with regard to gender, age and PASI score. Years of disease presentation and positive family history of psoriasis had a borderline statistical significance $(p=0.052)$. The mean age of psoriasis onset was lower in patients with psoriatic arthritis $(261 \pm 13.6$ years vs. $37.7 \pm 16.4$ years, $\mathrm{p}=0.002)$ and the NAPSI score was significantly higher in these patients [14 (4-28) vs $0(0-13), \mathrm{p}=0.001]$

Patients were asked if they experienced any kind of functional or aesthetic discomfort as a result of their nail changes, and a total of $63.3 \%$ of patients answered affirmatively to this question (Table 5). Most

TABLE 3: Characteristics of patients with and without nail involvement $(\mathrm{n}=57)^{*}$

\begin{tabular}{|c|c|c|c|}
\hline Characteristic & $\begin{array}{l}\text { With nail } \\
\text { changes } \\
(n=30)\end{array}$ & $\begin{array}{l}\text { Without nail } \\
\text { changes } \\
(n=27)\end{array}$ & p** \\
\hline Female gender & $16(53.3)$ & $19(70.4)$ & 0.295 \\
\hline Age, years & $51.8 \pm 15$ & $45.1 \pm 14.3$ & $0.090^{\mathrm{b}}$ \\
\hline $\begin{array}{l}\text { Disease onset, } \\
\text { years }^{\mathrm{a}}\end{array}$ & $27.6 \pm 14.9$ & $42.7 \pm 15.9$ & $0.001^{\mathrm{b}}$ \\
\hline$<20$ & $12(40)$ & $2(7.4)$ & 0.011 \\
\hline $20-59$ & $17(56.6)$ & $21(77.7)$ & 0.011 \\
\hline$\geq 60$ & $1(3.3)$ & $4(14.8)$ & 0.011 \\
\hline $\begin{array}{l}\text { Disease duration, } \\
\text { years }^{\mathrm{a}}\end{array}$ & $17.5 \pm 10.7$ & $9.1 \pm 9.7$ & $0.001^{c}$ \\
\hline PASI $^{\mathrm{a}}$ & $11.1 \pm 8.3$ & $6.5 \pm 6.1$ & $0.044^{c}$ \\
\hline$\leq 10$ & $16(53.3)$ & $22(81.5)$ & 0.049 \\
\hline$>10$ & $14(46.7)$ & $5(18.5)$ & 0.049 \\
\hline $\begin{array}{l}\text { Family history } \\
\text { of psoriasis }\end{array}$ & $12(40)$ & $2(7.4)$ & 0.011 \\
\hline Comorbidities & $19(63.3)$ & $20(70.1)$ & 0.623 \\
\hline Psoriatic arthritis & $13(43.3)$ & $1(3.7)$ & 0.002 \\
\hline 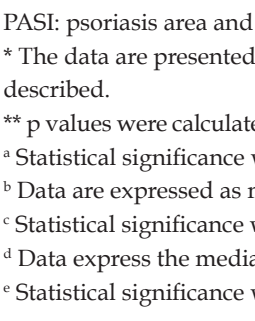 & $\begin{array}{l}\text { everity index. } \\
\text { s number of ind } \\
\text { by Fisher's exa } \\
\text { as established b } \\
\text { ean } \pm \text { standard } c \\
\text { as established b } \\
\text { and interquart } \\
\text { as established b }\end{array}$ & $\begin{array}{l}\text { iduals = n (\%), unles } \\
\text { test, unless otherwis } \\
\text { he Chi square test. } \\
\text { viation. } \\
\text { he t Student test. } \\
\text { range values (P25-I } \\
\text { he Mann Whitney te }\end{array}$ & $\begin{array}{l}\text { s otherwise } \\
\text { e described. }\end{array}$ \\
\hline
\end{tabular}


TABLE 4: Characteristics of patients whith and whithout psoriatic arthritis

\begin{tabular}{|c|c|c|c|}
\hline Characteristic & $\begin{array}{l}\text { With } \\
\text { psoriatic } \\
\text { arthritis } \\
(n=16)\end{array}$ & $\begin{array}{l}\text { Without } \\
\text { psoriatic } \\
\text { arthtritis } \\
(n=49)\end{array}$ & p** \\
\hline Female gendera & $10(62.5)$ & $32(65.3)$ & $>0,999^{b}$ \\
\hline Age, years & $45.9 \pm 13.6$ & $50.1 \pm 15$ & $0.326^{c}$ \\
\hline Disease onset, years & $26.1 \pm 13.6$ & $37.7 \pm 16.4$ & $0.013^{c}$ \\
\hline $\begin{array}{l}\text { Disease duration, } \\
\text { years }\end{array}$ & $19.5(1-40)$ & $10(1-41)$ & 0.052 \\
\hline $\begin{array}{l}\text { Family history of } \\
\text { psoriasis }^{\text {a }}\end{array}$ & $7(43.8)$ & $9(18.4)$ & 0.052 \\
\hline NAPSI & $18.3 \pm 16.5$ & $6.2 \pm 9.7$ & 0.001 \\
\hline PASI & $11.3 \pm 9.6$ & $8.3 \pm 7.44$ & $0.276^{\mathrm{d}}$ \\
\hline \multicolumn{4}{|c|}{$\begin{array}{l}\text { NAPSI, Nail Psoriasis Severity Index; PASI, Psoriasis Area and Ser } \\
{ }^{*} \text { Data express the median and interquartile range values (p25-p } \\
\text { ** The } p \text { values were calculated by Mann Whitney test, unles } \\
\text { described. } \\
{ }^{\text {a }} \text { All data are presented as number of individuals }=n(\%) \text {. } \\
\text { b Statistical significance was established by the Chi square test. } \\
{ }^{c} \text { Data are expressed as mean } \pm \text { standard deviation. } \\
\text { d p value was calculated by t Student test. } \\
{ }^{e} p \text { value was calculated by Fisher's exact test. }\end{array}$} \\
\hline
\end{tabular}

TABLE 5: Aesthetic discomfort and functional impairment related to nail psoriasis $(n=30)^{*}$

\begin{tabular}{llll}
\hline Characteristic & $\begin{array}{l}\text { With } \\
\text { discomfort } \\
\text { or functional } \\
\text { impairment } \\
\mathbf{n = 1 9}\end{array}$ & $\begin{array}{l}\text { Without } \\
\text { discomfort } \\
\text { or functional } \\
\text { impairment } \\
\mathbf{n = 1 1}\end{array}$ & p** \\
\hline Female gendera & $11(57.9)$ & $5(45.5)$ & $0.707^{\mathrm{b}}$ \\
Age, years & $46.7 \pm 16.7$ & $43.2 \pm 9.4$ & $0.522^{\mathrm{c}}$ \\
NAPSI & $21.2 \pm 13$ & $8.2 \pm 9.7$ & 0.040 \\
PASI & $12.4 \pm 8.3$ & $5.7 \pm 5.8$ & 0.204 \\
Number of & $9.7 \pm 4.4$ & $5.5 \pm 5.1$ & 0.032 \\
$\begin{array}{l}\text { affected nails } \\
\text { Under psoriatic } \\
\text { treatment }\end{array}$ & $16(84.2)$ & $9(81.8)$ & $>0.999^{\mathrm{b}}$ \\
\hline
\end{tabular}

NAPSI, Nail Psoriasis Severity Index. PASI, Psoriasis Area and Severity Index. *All data are presented as mean \pm standard deviation, unless otherwise described.

${ }^{* *} p$ value was calculated by Mann-Whitney test, except when otherwise described

${ }^{a}$ Data expressed as $\mathrm{n}=$ number of individuals $(\%)$

${ }^{\mathrm{b}} \mathrm{p}$ value was calculated using Chi square test.

${ }^{c} p$ value was calculated using Student's t test.

${ }^{\mathrm{d}} \mathrm{p}$ value was calculated using Fisher's exact test.

patients who reported feeling discomfort were currently under some sort of treatment for psoriasis vulgaris $(84.2 \%)$. They also more often had higher NAPSI scores and a greater number of nails affected. There were no significant differences between genders, age groups, PASI and the presence of a treatment.

\section{DISCUSSION}

Although nail manifestations are common in patients with psoriasis, they are only recently being the target of standardized quantification and detailed characterization. In Brazil, there are only a few studies on nail psoriasis, especially when considering epidemiological and morphological patterns of NP in our population.

The main current knowledge on NP comes from European studies. Compared to them, the prevalence of NP obtained in this sample of Brazilian patients was similar to that found in Spanish $(47.7 \%)$ and German patients (40.9\%). 10,11 Brazzelli and colleagues report a prevalence of NP of $76.9 \%$ in a sample of 137 Italian patients. ${ }^{20}$ Similar results were found in a study with 106 Polish patients $(78.3 \%) .{ }^{21}$ In the Brazilian study by Ribeiro and colleagues, which focused on the periungueal capillaroscopy of psoriatic patients, $37 \%(n=46)$ of patients had nail disease, defined by pitting or onychodystrophy. ${ }^{22}$ The differences in the prevalence of NP in the different populations reflect the difficulty in establishing an exact value of NP prevalence in patients with cutaneous psoriasis or its variability.

Most patients had a mild skin condition, which may have been influenced by the fact that most patients were already under some type of treatment with focus on cutaneous psoriasis. This factor may even have interfered with the NAPSI scores and the prevalence of nail psoriasis. However, this shows that physicians need to pay attention to nail findings and to complaints related to the nails, because even patients who were under treatment reported some type of functional or aesthetic discomfort. Still, this sample was not composed of patients who were under immunobiological therapy - which has proven to be effective in the treatment of nail psoriasis. . $^{43,24}$

The exclusion of all cases of onychomycosis from the analysis related to nail psoriasis was made in order to minimize potential bias. That is because onychomycosis may present with clinical features that are similar to nail psoriasis. ${ }^{25}$ Direct examination and culture were used for this purpose; however, we point out the absence of nail biopsy procedures as a study limitation. This could have helped to achieve a higher accuracy for the diagnosis of onychomycosis. Furthermore, it is estimated that the presence of onychomycosis is observed in about 4.6 to $30 \%$ of patients with PU, which points out to a possible exclusion of cases with this association, underestimating the data obtained on prevalence. $^{25}$

NP was associated with earlier onset of psoriasis and cases of longer disease presentation, in accordance to previous studies from other authors. ${ }^{10,26,27}$ The highest occurrence of nail abnormalities related to older ages, which was observed in this study, can be 
associated with the higher frequency of nail problems that is observed in advanced age due to deficits in peripheral circulation, neuropathy and repetitive local trauma. ${ }^{21}$

$\mathrm{NP}$ was also associated with more extensive cutaneous disease and presence of joint involvement. Such observations have been described by several authors. ${ }^{6,8,11,28}$ The close microanatomical relationship between the nail unit and the musculoskeletal system is a plausible reason for the association between the ungueal and joint findings. Through this link, the extension of the local inflammation - related to an enthesitis at the terminal phalanx - could cause the changes found in the nails. ${ }^{29}$ Therefore, it is estimated that an average of $80 \%$ of patients with PA will present nail involvement at some point of their lives. ${ }^{6,20,29,30}$ The greater extent of skin involvement associated with the presence of nail psoriasis can be elucidated through the following equation: for each one-point increase in the severity of skin involvement, a 10-point increase in the severity of nail involvement is expected. This equation was proposed by Hallaji and colleagues in a study that evaluated 100 patients, and correlated the PASI and the NAPSI. ${ }^{28}$

For some authors, the most common sign of $\mathrm{NP}$ is the pitting, ${ }^{31,32}$ while for others the main finding is subungueal hyperkeratosis. ${ }^{21}$ Attempting to discriminate and compare the ungueal findings identified by the NAPSI in patients with psoriasis and in a control group of healthy patients, a Dutch study identified onycholysis and splinter hemorrhages as the most frequent signals associated with psoriasis. ${ }^{33}$ Similar to that, onycholysis was the most common finding in our study and in the study by Brazzelli and colleagues. ${ }^{20}$ We find important to emphasize that the NAPSI score used in the present study constitutes an excellent validated tool to analyze the patterns and quantify the ungueal involvement. However, it only takes into account six features related to nail psoriasis (onycholysis, subungual hyperkeratosis, oil stain, pitting, splinter hemorrhages, leukonychia, crumbling, and red spots in the lunula), and does not consider any other features which are also known to be related to psoriasis, such as Beau's lines, for example. ${ }^{1}$

Moreover, the NAPSI score only takes into account the objective impression of the examiner and is therefore unable to predict the impact of these scores on the quality of life of patients with PU. Studies measuring quality of life impairment in these patients showed that $51.8 \%$ complained of pain in the nails, $58.9 \%$ reported restrictions in their daily life, ${ }^{7}$ and $90 \%$ considered the cosmetic appearance of their nails to be disturbing. ${ }^{6}$ In this context, in order to include a subjective variable dedicated to the patient into our study, we questioned the patients whether they experienced any aesthetic or functional discomfort in their daily activities. Such questioning may be considered too simple when compared with the NPQ10 (Nail Psoriasis Quality of Life Scale), designed to assess the quality of life in patients with nail psoriasis. ${ }^{34}$ However, the latter was not used because a validated translation into Portuguese is not yet available.

\section{CONCLUSION}

As far as we know, this study is the first study in Brazil on the prevalence of nail changes in patients with plaque-type psoriasis. It focused on the morphological characteristics of the ungueal presentation, and showed similar results to that previously published internationally. The frequency of nail findings in the studied population, which consisted mostly of patients who were already using systemic drugs and who had cutaneous severity classified as mild, suggests that nail involvement may be underestimated by doctors. In this context, it is essential that the dermatological evaluation of psoriatic patients take in consideration the nail problem, in order to optimize treatment and improve patients's satisfaction. $\square$ 


\section{REFERENCE}

1. J iaravuthisan MM, Sasseville D, Vender RB, Murphy F, Muhn CY. Psoriasis of the nail: anatomy, pathology, clinical presentation, and a review of the literature on therapy. J Am Acad Dermatol. 2007;57:1-27.

2. Ren V, Dao H J r. Potential role of ixekizumab in the treatment of moderate-tosevere plaque psoriasis. Clin Cosmet Investig Dermatol. 2013:6:75-80.

3. Sánchez-Regaña M, Umbert P. Diagnosis and management of nail psoriasis. Actas Dermosifiliogr. 2008;99:34-43.

4. Sánchez-Regaña M, Aldunce Soto MJ, Belinchón Romero I, Ribera Pibernat M, Lafuente-Urrez RF, Carrascosa Carrillo J M, et al. Evidence-Based Guidelines of the Spanish Psoriasis Group on the Use of Biologic Therapy in Patients With Psoriasis in Difficult-to-Treat Sites (Nails, Scalp, Palms, and Soles). Actas Dermosifiliogr. 2014. pii: S0001-7310(14)00208-7.

5. Schons KR, Knob CF, Murussi N, Beber AA, Neumaier W, Monticielo OA. Nail psoriasis: a review of the literature. An Bras Dermatol. 2015;90:312-7.

6. Baran R. The burden of nail psoriasis: an introduction. Dermatology. 2010;221:1-5.

7. de J ong EM, Seegers BA, Gulinck MK, Boezeman J B, van de Kerkhof PC. Psoriasis of the nails associated with disability in a large number of patients: results of a recent interview with 1,728 patients. Dermatology. 1996;193:300-3.

8. Augustin M, Krüger K, Radtke MA, Schwippl I, Reich K. Disease severity, quality of life and health care in plaque-type psoriasis: a multicenter cross-sectional study in Germany. Dermatology. 2008;216:366-72.

9. Wilson FC, Icen M, Crowson CS, McEvoy MT, Gabriel SE, Kremers HM. Incidence and clinical predictors of psoriatic arthritis in patients with psoriasis: a populationbased study. Arthritis Rheum. 2009;61:233-9.

10. Augustin M, Reich K, Blome C, Schäfer I, Laass A, Radtke MA. Nail psoriasis in Germany: epidemiology and burden of disease. Br J Dermatol. 2010;163:580-5.

11. Armesto S, Esteve A, Coto-Segura P, Drake M, Galache C, Martínez-Borra J, et al. Nail psoriasis in individuals with psoriasis vulgaris: a study of 661 patients. Actas Dermosifiliogr. 2011;102:365-72.

12. Romiti R. Psoríase Ungueal. In: Arruda LHF, Takada LP, Bázzan ACB, editores. Compêndio de psoríase. Rio de J aneiro: Elsevier; 2010. p.80-6.

13. Cappelleri J C, Bushmakin AG, Harness J, Mamolo C. Psychometric validation of the physician global assessment scale for assessing severity of psoriasis disease activity. Qual Life Res. 2013;22:2489-99.

14. Szepietowski J C, Salomon J. Do fungi play a role in psoriatic nails? Mycoses. 2007;50:437-42.

15. Augustin M, Ogilvie A. Methods of outcomes measurement in nail psoriasis. Dermatology. 2010;221:23-8.

16. Klaassen KM, van de Kerkhof PC, Bastiaens MT, Plusjé LG, Baran RL, Pasch MC. Scoring nail psoriasis. J Am Acad Dermatol. 2014;70:1061-6.

17. Roberts WE. Skin type classification systems old and new. Dermatol Clin. 2009;27:529-33, viii.

18. Finlay AY. Current severe psoriasis and the rule of tens. $\mathrm{Br} J$ Dermatol. 2005;152:861-7.

19. Baker C, Mack A, Cooper A, Fischer G, Shumack S, Sidhu S, et al. Treatment goals for moderate to severe psoriasis: An Australian consensus. Australas J Dermatol. 2013:54:148-54.

20. Brazzelli V, Carugno A, Alborghetti A, Grasso V, Cananzi R, Fornara L, et al. Prevalence, severity and clinical features of psoriasis in fingernails and toenails in adult patients: Italian experience. J Eur Acad Dermatol Venereol. 2012;26:1354-9.

21. Salomon J, Szepietowski J C, Proniewicz A. Psoriatic nails: a prospective clinical study. I Cutan Med Surg. 2003;7:317-21.

22. Ribeiro CF, Siqueira EB, Holler AP, Fabrício L, Skare TL. Periungual capillaroscopy in psoriasis. An Bras Dermatol. 2012;87:550-3.

23. Luger TA, Barker J, Lambert J, Yang S, Robertson D, Foehl J, et al. Sustained improvement in joint pain and nail symptoms with etanercept therapy in patients with moderate-to-severe psoriasis. J Eur Acad Dermatol Venereol. 2009;23:896-904.

24. Griffiths CE, Girolomoni G. Does p40-targeted therapy represent a significant evolution in the management of plaque psoriasis? J Eur Acad Dermatol Venereol. 2012;26:2-8.
25. Natarajan V, Nath AK, Thappa DM, Singh R, Verma SK. Coexistence of onychomycosis in psoriatic nails: a descriptive study. Indian J Dermatol Venereol Leprol. 2010;76:723.

26. Ferrándiz C, Pujol RM, García-Patos V, Bordas X, Smandía JA. Psoriasis of early and late onset: a clinical and epidemiologic study from Spain. J Am Acad Dermatol. 2002;46:867-73.

27. Garg N, Truong B, Ku JH, Devere TS, Ehst BD, Blauvelt A, et al. A novel, short, and simple screening questionnaire can suggest presence of psoriatic arthritis in psoriasis patients in a dermatology clinic. Clin Rheumatol. 2014 May 15. [Epub ahead of print].

28. Hallaji Z, Babaeijandaghi F, Akbarzadeh M, Seyedi SZ, Barzegari M, Noormohammadpour $P$, et al. A significant association exists between the severity of nail and skin involvement in psoriasis. J Am Acad Dermatol. 2012;66:e12-3.

29. McGonagle $\mathrm{D}, \operatorname{Tan} \mathrm{AL}$, Benjamin $\mathrm{M}$. The nail as a musculoskeletal appendage-implications for an improved understanding of the link between psoriasis and arthritis. Dermatology. 2009;218:97-102.

30. Williamson L, Dalbeth N, Dockerty J L, Gee BC, Weatherall R, Wordsworth BP. Extended report: nail disease in psoriatic arthritis--clinically important, potentially treatable and often overlooked. Rheumatology (Oxford). 2004;43:790-4.

31. Mukai MM, Poffo IF, Werner B, Brenner FM, Lima Filho J H. NAPSI utilization as an evaluation method of nail psoriasis in patients using acitretin. An Bras Dermatol. 2012;87:256-62

32. Tan ES, Chong WS, Tey HL. Nail Psoriasis: A Review. Am J Clin Dermatol. 2012;13:375-88

33. van der Velden $\mathrm{HM}$, Klaassen $\mathrm{KM}$, van de Kerkhof PC, Pasch MC. Fingernail psoriasis reconsidered: A case-control study. J Am Acad Dermatol. 2013;69:245-52.

34. Ortonne JP, Baran R, Corvest M, Schmitt C, Voisard JJ, Taieb C. Development and validation of nail psoriasis quality of life scale (NPQ10). J Eur Acad Dermatol Venereol. 2010;24:22-7.
M AILING ADDRESS:
Karen Regina Rosso Schons
BR 285, São José
99052-900 - Passo Fundo - RS
Brazil.
E-mail: ka.bras@bol.com.br

How to cite this article: Schons KRR, Beber AAC, Beck MO, Monticielo OA. Nail involvement in adult patients with plaque-type psoriasis: prevalence and clinical features. An Bras Dermatol. 2015;90(3):314-9. 